University of Nebraska - Lincoln

DigitalCommons@University of Nebraska - Lincoln

USDA National Wildlife Research Center - Staff Publications
U.S. Department of Agriculture: Animal and Plant Health Inspection Service

2013

\title{
Monitoring wild pig populations: a review of methods
}

\author{
R. M. Engeman \\ USDA-APHIS-Wildlife Services, s_r100@yahoo.com \\ G. Massei \\ Animal Health Veterinary Laboratory Agency \\ M. Sage \\ Wildlife, Environment and Expertises \\ M. N. Gentle \\ Robert Wicks Pest Animal Research Centre
}

Follow this and additional works at: https://digitalcommons.unl.edu/icwdm_usdanwrc

Part of the Life Sciences Commons

Engeman, R. M.; Massei, G.; Sage, M.; and Gentle, M. N., "Monitoring wild pig populations: a review of methods" (2013). USDA National Wildlife Research Center - Staff Publications. 1496.

https://digitalcommons.unl.edu/icwdm_usdanwrc/1496

This Article is brought to you for free and open access by the U.S. Department of Agriculture: Animal and Plant Health Inspection Service at DigitalCommons@University of Nebraska - Lincoln. It has been accepted for inclusion in USDA National Wildlife Research Center - Staff Publications by an authorized administrator of DigitalCommons@University of Nebraska - Lincoln. 


\title{
Monitoring wild pig populations: a review of methods
}

\author{
R. M. Engeman • G. Massei • M. Sage • M. N. Gentle
}

Received: 23 May 2013 / Accepted: 10 July 2013 / Published online: 24 July 2013

(C) Springer-Verlag Berlin Heidelberg (outside the USA) 2013

\begin{abstract}
Wild pigs (Sus scrofa) are widespread across many landscapes throughout the world and are considered to be an invasive pest to agriculture and the environment, or conversely a native or desired game species and resource for hunting. Wild pig population monitoring is often required for a variety of management or research objectives, and many methods and analyses for monitoring abundance are available. Here, we describe monitoring methods that have proven or potential applications to wild pig management. We describe the advantages and disadvantages of methods so that potential users can efficiently consider and identify the option(s) best suited to their combination of objectives, circumstances, and resources. This paper offers guidance to wildlife managers, researchers, and stakeholders considering population monitoring of wild pigs and will help ensure that they can fulfill their monitoring objectives while optimizing their use of resources.
\end{abstract}

Keywords Abundance index $\cdot$ Density estimate $\cdot$ Feral hog . Sus scrofa . Wild boar

Responsible editor: Philippe Garrigues

R. M. Engeman $(\bowtie)$

National Wildlife Research Center, 4101 LaPorte Ave, Fort Collins, CO 80521-2154, USA

e-mail: richard.m.engeman@aphis.usda.gov

G. Massei

Animal Health Veterinary Laboratory Agency, Sand Hutton, York YO41 1LZ, UK

\section{Sage}

Wildlife, Environment and Expertises, 25 rue de la Grette, 25000 Besancon, France

M. N. Gentle

Robert Wicks Pest Animal Research Centre, Biosecurity

Queensland, 203 Tor Street, Toowoomba QLD 4350, Australia

\section{Introduction}

Wild pigs, wild boars, feral hogs, and razorbacks are just a few of the many names applied to wild populations of Sus scrofa. The species has a broad native range and even broader range as an exotic invasive species (e.g., Massei et al. 2011). The negative impacts of native or invasive wild pigs on human activities range from damage to agricultural crops to livestock predation, reduction of species abundance in plant and animal communities (especially in fragile wetlands habitats), and threats to rare species and to wild pigs being a reservoir for disease transmission to livestock or humans (Choquenot et al. 1997; Corn et al. 2005, 2009; Engeman et al. 2007, 2010, 2011; Massei and Genov 2004; Ruiz-Fons et al. 2008; Seward et al. 2004). The species was listed as among 100 of the "World's Worst" invaders by the IUCN's Invasive Species Specialist Group (Lowe et al. 2004). In contrast, wild pigs, both native and introduced, are often valued in many areas as a game species for commercial, recreational, or subsistence hunting (Ramsay 1994; Meurk 2011). In native ranges, they can be a valued component of the natural heritage (Leaper et al. 1999) and an important food source for large predators such as wolves (e.g., Meriggi et al. 1996). In some places, wild pigs are viewed as both desired game animal and undesired invasive species (Choquenot et al. 1996; Koichi et al. 2012).

The management of wild pig populations or the mitigation of their impact often requires knowledge of local abundance information. "If you can't monitor it, you can't manage it" is an old adage highly applicable to the management of wild pigs. In this paper, we briefly describe a useful survey structure with associated calculations and an array of monitoring methods that can be used in wild pig management applications, and we highlight their constraints and advantages. Monitoring the geographic distribution and expansion of pig populations is a related aspect of pig population management (e.g., Corn et al. 2005; Meyerson et al. 2008), 
though in this paper we restrict our focus to methods for assessing population abundance of wild pigs within defined areas.

Wild pig population monitoring is required for a variety of management or research objectives, and many observational methods and metrics for abundance are available for consideration (see Table 1). One thing in common with virtually all monitoring objectives is that there is little value in a single point estimate; conversely, multiple estimates are useful to assess trends across time or geographical space. Trends over time can be as simple as monitoring population fluctuations in a natural setting or evaluating the impacts of a management action such as culling wild pigs from an area. To monitor population changes, it would be ideal to know the exact number of wild pigs in a given area, but in reality, this is a rare circumstance for wild populations, and population size is commonly assessed through sampling procedures (Caughley 1977). Density estimation procedures such as mark-capture methods (e.g., Otis et al. 1978) and distance sampling (e.g., Burnham et al. 1980) attempt to estimate the actual number or density of animals in an area, but these procedures are often difficult or expensive to implement, and they may require difficult-to-meet analytical assumptions that when violated result in estimates of questionable quality (see Krebs (1998), Leidloff (2000), and McKelvey and
Pearson (2001) for an examination of potential problems with mark-recapture methods and Burnham et al. (1980) for a similar discussion on line transect methods). As wild pigs can be destructive and invasive animals or vectors of a disease, managers can be reluctant to release captured animals for mark-recapture purposes (unless capture-markrecapture is carried out by indirect methods not requiring capture and release).

Frequently, problems couched in terms of absolute density can be redefined so that indices reflecting population abundance will provide an efficient solution (Caughley 1977; Engeman 2003, 2005; Krebs 1998). Examples include tracking rates, pellet counts, capture rates, bait consumption, or visual observations, among many possibilities. While indices are not estimates of actual population numbers, properly constructed indices can be applied to make relative comparisons between populations or to monitor trends within a population (e.g., Caughley 1977; Krebs 1998). Despite their widespread use, applying indices to assess wildlife populations is not universally accepted (e.g., Anderson 2001; Johnson 2008). However, the criticisms leveled at indices in the literature have focused primarily at statistically unstructured counts (mostly for birds) (Anderson 2001; Johnson 2008) and have resulted in perceptions of general indictments of all indexing procedures. Engeman (2003)
Table 1 Summary of the type of survey methods, with the means of data collection (measurement tools), the type of measurements collected (potential measurements), and the abundance measurement

\begin{tabular}{|c|c|c|c|}
\hline Type of survey & Measurement tool(s) & Potential measurements & Potential metrics of abundance \\
\hline Track & Tracking plots & $\begin{array}{l}\text { Number of track intrusions } \\
\text { Presence-absence }\end{array}$ & Index \\
\hline Dung & $\begin{array}{l}\text { Defined areas for Pellet counts } \\
\text { DNA analysis }\end{array}$ & $\begin{array}{l}\text { Number of pellet groups } \\
\text { Number individuals and "recaptures" }\end{array}$ & $\begin{array}{l}\text { Index } \\
\text { Known to be alive } \\
\text { M-R density estimate }\end{array}$ \\
\hline Road counts (counts from vehicles) & $\begin{array}{l}\text { Human observers } \\
\text { Spotlight } \\
\text { Night vision } \\
\text { Thermal imaging }\end{array}$ & $\begin{array}{l}\text { Counts } \\
\text { Distance to animals observed }\end{array}$ & $\begin{array}{l}\text { Index } \\
\text { Density estimate }\end{array}$ \\
\hline Aerial surveys & $\begin{array}{l}\text { Human observers } \\
\text { Video } \\
\text { Thermal imaging }\end{array}$ & $\begin{array}{l}\text { Counts } \\
\text { Number of animals in strip transect(s) } \\
\text { Distance to animals from aerial transect }\end{array}$ & $\begin{array}{l}\text { Index } \\
\text { Density estimate }\end{array}$ \\
\hline Animal marking & $\begin{array}{l}\text { Trap and mark } \\
\text { Bait markers }\end{array}$ & $\begin{array}{l}\text { Resight/recapture } \\
\text { Capture and check for mark }\end{array}$ & $\begin{array}{l}\text { Density estimate } \\
\text { Known to be alive index }\end{array}$ \\
\hline Take rates & Hunter survey & $\begin{array}{l}\text { Hunter take } \\
\text { Hunter effort }\end{array}$ & $\begin{array}{l}\text { Take index } \\
\text { Take/effort index }\end{array}$ \\
\hline Camera & Camera traps & $\begin{array}{l}\text { Number photographed } \\
\text { Resight (recapture) }\end{array}$ & $\begin{array}{l}\text { Index } \\
\text { Known to be alive index } \\
\text { Density estimate }\end{array}$ \\
\hline Plot occupancy & Geographic units & Assessed occupancy within a unit & $\begin{array}{l}\text { Density estimate } \\
\text { Occupancy index }\end{array}$ \\
\hline
\end{tabular}

(potential metrics of abundance). More details of usage and analyses for each method are discussed in the text 
pointed out that the influences decried as invalidating the use of unstructured count indices would statistically invalidate any sampling study, including population estimation procedures (see also Johnson 2008). A properly defined and applied indexing procedure in most cases will fulfill monitoring objectives while optimizing resources to obtain the information.

\section{Desirable qualities for a population monitoring method}

Ideally, methods aimed at assessing population size or estimating population trends should (1) be practical to use in field conditions, (2) sensitive enough to reflect changes in numbers or trends, (3) rely on a minimum number of assumptions that can be relatively easily met, and (4) be associated with statistical methodology that allows valid comparisons between areas or time points.

\section{Practicality}

A method should be easy to understand and practical to apply, as these are often prime deciding factors for choosing between different methods. The method should be userfriendly, with the procedures and concepts for taking samples or recording information easily understood and with little chance for misinterpretation. Methods must also impose minimal inconvenience on landowners and managers to be acceptable or they are unlikely to be implemented (i.e., any methods that interfere with normal operations by the property owner/manager). The more practical methods (effective low-labor, low-cost methods) naturally make greater sample sizes more feasible (Engeman 2005; Thomas et al. 2013) and reduce survey costs (Franzetti et al. 2012).

\section{Sensitivity}

A method should reflect changes in population size and trends, whether making simultaneous comparisons among multiple populations or monitoring for change within the same population. That is, the measurements upon which the method is based should change if the population changes. For instance, the amount of habitat damaged by pigs within highly similar areas might indicate differences in wild pig population sizes between the areas. However, the longevity of damage (e.g., the time since rooting occurred) makes it an inaccurate measure from which to gauge short-term changes within wild pig populations (such as from control efforts). Similarly, using activity signs such as pellet counts relies on the persistence of these signs which may vary dramatically between seasons and environments (Massei et al. 1998). As described later, rigorous design of observation methods can alleviate such issues.
Precision and variance estimation

Given an appropriate observation method, the ability to detect statistical differences between estimates increases with the precision (decreasing variance) of the estimates. This also highlights a subtle contrast between density estimation and indexing. Density estimation strives to identify actual population abundance directly, whereas indexing procedures use indicators for detecting differences in abundance. Thus, general applications for density estimation place a premium on accuracy (low bias), but because the primary applications for indices are comparative, precision is of the utmost importance to allow sensitive statistical comparisons (e.g., Caughley and Sinclair 1994). A method that is easily applied in the field will likely encourage more observations, with a consequent improvement in precision.

Since precision is essential to an index, the data collection must be structured to provide an estimate of variance, which in turn allows for the application of standard statistical procedures. Often observations are made and an index is produced with little attention to the statistical treatment of data. In these instances, the only means to estimate variance is to first subdivide the data into units that can contribute to the variance calculations. This approach, especially if done post hoc, can produce variance estimates that vary subjectively with the definition of the units.

\section{Robustness}

The most robust inferences are produced if the estimate and associated variance rely on as few assumptions as possible about the data structure and the distribution of the observations. An index heavily reliant on analytical assumptions is often of minimal use to the investigator. Violation of analytical assumptions is routinely quoted as the main problem of density estimation methods (see Krebs 1998 for a general overview) and can be a compelling reason, besides labor, to apply an index rather than estimating density.

Besides the above four qualities, other characteristics can make a procedure more informative. Observation methods allowing simultaneous monitoring of multiple species achieve economy of effort. Such information may be used to assess potential relationships between pig abundance and the abundance and impacts for sympatric species. Also, if information on geographic location is collected along with the observations, then spatial characteristics of the population(s) may also be described.

\section{Observation concepts}

Observation methods lead to abundance assessments by recording either animals or their sign. Observing and 
counting of wild pigs has been undertaken by a variety of techniques, either directly (i.e., an observer sighting animals) or indirectly (i.e., remote cameras recording images or footage of animals). Direct observation of animals by one or more observers historically has been a commonly used method, although technological improvements with concomitant cost reductions are increasing the use of indirect count methods. Techniques employing observer(s) to count directly wild pigs include field observations (such as walked or driven counts and counts from fixed locations), "battue counts" (where dogs may be used to flush wild pigs for counting), aerial surveys (from a helicopter or fixed-wing aircraft), and spotlight counts (walked or from vehicle using either a spotlight or thermal imagery) (Choquenot et al. 1996; Hone and Martin 1998; Hone 2012; Massei et al. 2011). Indirect counts of wild pigs may be undertaken through (1) placing remote cameras at locations with fresh signs of pig activity (such as watering points, trails, rooting), (2) through actively attracting wild pigs to the location (i.e., by using food or olfactory attractants), or (3) by using camera grids where camera traps are evenly distributed throughout the whole study area.

Wild pigs leave conspicuous field sign such as rooting, characteristic tracks, and dung, which can be used as reliable means for detecting their presence and quantifying their relative abundance. The species willingness to use dirt roads or trails as travel routes in many habitats has made tracking methodologies valuable for monitoring populations. "Nests" made in vegetation by sows prior to farrowing can also provide indications of presence although they are uncommon. Other signs left by wild pigs include wallows near water points, tusk marking of trees (or vegetation and fence posts), and mud and hair left on trees and fences. However, the potential user needs to consider a number of factors, including the applicability and situations where the method may be used, the repeatability of the method, and the practicality of the method (Engeman 2005; Engeman and Witmer 2000).

\section{A general observational structure}

There has been a tremendous array of monitoring procedures applied to many wildlife species. Each combination of observation, sampling frame, and computation procedure results in a parameter estimate for a population characteristic that can be regarded as an indicator of animal abundance. We summarize a sampling structure in which many existing, or new, observation and measurement methods can be couched so that the calculated estimates (index values) possess useful statistical properties. The key components include defining where the observations are taken, the time dimension for taking observations, the measurements to make, and the data structure and analytical procedures (Engeman 2005) for calculating an index and its variance estimate.

Even with the best designed study, the highest quality data, and proper analytical methods, comparisons between areas, years, or seasons must be based on the same indicators and free of confounding effects (Engeman 2005; Allen et al. 2011). That is, compare apples to apples. For example, pig activity can vary in magnitude seasonally and across habitats. To examine for population changes from 1 year to the next, it would be inappropriate to assess the pig population in one season of 1 year and then compare it in a different season in another year, because it would be impossible to attribute differences to population changes or due to the activity being different in different seasons. This is an important consideration for indices, as they are usually a function of abundance and detectability, and differences in detectability are much more likely to mask inferences on changes in abundance if improper statistical designs are used (e.g., Allen et al. 2011).

\section{Observation stations}

The locations for making observations are referred here generically as stations. For example, each station might be a plot for observing tracks or other sign, a camera location, a point where animal counts are made, a site where bait consumption is measured, or a strip transect searched for dung. Stations might even be the area around commercial swine production facilities if the objective is to index potential contact between wild and domestic swine (Engeman et al. 2011).

To monitor a population within an area, observation stations should be set throughout the survey area of interest. The distribution of observation stations must be carefully considered relative to efficiency in obtaining adequate measurements of the animals being monitored and avoiding bias in the results that could be induced by station placement. Rarely do animals operate in a spatially random pattern. It is important to keep in mind that the objective is not to sample the geographical area, but rather the population residing in that area. Station locations may take advantage of behavioral characteristics by placement where they would most likely intersect the usual activities of the target animals (Engeman et al. 2002). This is similar in concept to the capture of animals. Capture devices are not placed with complete randomness, but rather are placed where an animal is most likely to encounter the capture device. Consider a tracking plot example for collecting data. Many species preferentially use the path of least resistance for travel, which in many areas includes dirt roads or tracks as travel ways, and this has been documented for wild pigs in many areas of the world (Allen and Engeman 1995; Elledge 2011; Engeman et al. 2007; Jiang et al. 2006; Theurkauf and Rouys 2008). 
Placement of stations along such travel ways is an efficient means to obtain observations. If such travel ways are distributed throughout the area of interest, they can provide a means for station placement that is an efficient and representative sampling of the population using the surrounding habitat. Care and common sense must be applied when choosing to take advantage of these behavioral characteristics for monitoring animals. If roads or tracks are not dispersed through the area of interest, then observations only from them would be less likely to be representative of the population throughout the area. If multiple assessments are to be made through time on the same area, then the same station locations should be used, if possible (e.g., Ryan and Heyward 2003). If the area of interest is comprised of different habitat types, then it is advisable to stratify station placement according to habitat type, thus helping to insure that the calculated index reflects the population throughout the area rather than being overly biased towards (or away from) a particular subset of available habitats.

Food such as maize or locally abundant fruits can be used to attract pigs to observation stations; though when animals are actively attracted to observation stations through feeding or olfactory attractants, one should be cautious regarding the influence of dominant individuals or groups on the other population members. Wild pig-specific feeders such as the Boar-Operated-System (BOS) or Hoghopper ${ }^{\mathrm{TM}}$ that allow selective feeding by wild pigs could be used to attract this species to stations (Lapidge and Wishart 2010; Massei et al. 2010; Campbell et al. 2011). However, the availability and seasonality of food can influence the likelihood of visitation, so caution must be used when using such observations to compare abundance between sites or time periods (e.g., Saunders et al. 1993).

The size and shape of stations should be consistent. This applies to area dimensions of the stations, as well as to time, weight, or any other characteristic of the stations. Thus, not only should stations such as tracking plots have consistent sizes within a study (e.g., rectangular dimensions), but baittake stations should each start with the same amount of bait and be observed for the same amount of time (with more bait supplied than is likely to be consumed in the observation period). Stations for animal counts should be observed for the same length of time and within the same distance limit. Camera stations should have consistent estimated focal ranges (the area in the camera's view), the same equipment capabilities and settings (such as for minimal time between photos), and with sufficient battery life and memory capacity to obtain and store all potential photographic opportunities.

An animal "visit" to a station is not always a straightforward observation. To insure consistency among observations, a "visit" should be defined a priori. For instance, using camera traps as an example, the time set to elapse between successive photos can define individual visits to the station.
If individuals are uniquely distinguishable (e.g., by size, sex, and coat color), then the number of individuals may be the measure of interest. For tracking plot observations, the number of intrusions by a species into a tracking plot is commonly used to monitor many wildlife species globally (e.g., Engeman et al. 2001, 2007; USDA 2011).

\section{Time dimension}

Animal activity often is variable over even short time frames. Thus, to account for variability over time, the stations are best observed on more than one occasion during an assessment period. Typically, this means taking measurements at each station on each of multiple days, but for some applications this could mean taking measurements at regular times, such as every day or every other day. For simplicity, the time dimension will be referred to here as a day effect, representing a common situation where observations at each indexing session would be made on multiple, usually consecutive, days. The time elapsed between successive observations at each station should remain constant. For example, assume observations are to be made at three time points. The time lapsed for accumulation of data should be constant at each of the three observation times. If tracking plots are to be observed $24 \mathrm{~h}$ after plot preparation, then each successive observation of the plots should also be made $24 \mathrm{~h}$ after plot preparation.

\section{Measurements}

Many types of measurements can fit the above observational structure, including the general categories of animal counts, measurements of animal sign, and catch per unit effort (e.g., via dung counts, cameras, etc.). The observations taken at each station are most valuable if they are not binary (i.e., presence-absence), but offer a continuum of possible measurements (e.g., Allen et al. 1996, 2011; Engeman 2005; Engeman and Allen 2000). The variety of nonbinary indexing measurements at different types of observation stations includes, for example, the number of intrusions by each species of animal onto a dirt tracking plot, the proportion or amount of bait consumed, and the number of individuals (of each species) observed in a (a priori defined) fixed amount of time within a fixed distance at each station (e.g., Engeman 2005; Engeman and Whisson 2003; Engeman and Witmer 2000).

Often, potentially continuous measures have been neglected in favor of binary observations, i.e., presenceabsence measures at each station. Binary observations often have been made because a continuous measurement was more difficult to make or was not considered. For example, tracking plots are easier to record as showing activity or not, without accurately recording the intensity of activity at each 
station. Nevertheless, reduction of potentially continuous data to binary observations is easily demonstrated to have less descriptive ability and result in a greater opportunity for erroneous inferences (Engeman et al. 1989), and this principle has been especially well-demonstrated for tracking plot data (e.g., Allen et al. 1996, 2011; Blaum et al. 2008; Engeman 2005; Engeman et al. 2000, 2002).

A corollary to the use of continuous rather than binary measures is that stations should be designed so that total saturation at a station is unlikely. That is, not all bait at a bait station would be consumed, or a tracking plot would not be totally obliterated by animal activity, cameras are set, and photos downloaded such that memory and battery are unlikely to be fully consumed. Thus, even if all stations receive activity, differences in intensity among stations can still be observed.

In practice, it would be unreasonable to assume that each station would contribute data each day. The common reasons why observations can be lost at a station include interference of tracking plots from livestock or vehicle traffic, technical or climatic factors that can cause cameras to malfunction, observations at some stations that may be missed due to unforeseen access restrictions, and the public interfering with observation stations. Thus, the number of stations contributing data each day is allowed to vary for an analytic procedure to be generally useful.

Similarly, to assume that stations are geographically uncorrelated, or that observation days are uncorrelated, would be biologically unreasonable in most circumstances. For example, animals may roam greater distances than those separating the stations. Stations that are closer together may share more environmental characteristics than do more distantly separated stations. Furthermore, environmental or climatic conditions should not be assumed to be unrelated across days of observation. In this sampling framework, stations are not assumed to be independent of each other nor are days assumed independent of each other. Thus, analytical procedures must not rely on potentially unrealistic assumptions of independence (Engeman 2005).

\section{Applications, advantages, and limitations of observation methods}

There are many observation methods applied in many circumstances to monitor wild pig populations. This section briefly describes prominent observation methods that can be used to quantitatively monitor wild pig populations. The possibilities for observation methods are limited only by the creativity of the investigator. Fitting whatever method is used into the observational structure described above can help insure that the population monitoring provides meaningful results. When considering observation methods for a particular application, readers are encouraged to use the following method descriptions as introductory guidelines and then research the method(s) in greater detail before coming to a final decision. In any case, testing the method in advance in similar circumstances as its intended application is highly desirable.

\section{Tracking plots}

Tracking plots have been successfully used to monitor wild pig abundance in a variety of circumstances using a variety of plot configurations (e.g., Allen et al. 1996; Engeman et al. 2001, 2002, 2007; USDA 2011). In each case, plots were passive (no attractants) and placed on dirt roads or tracks to intercept the normal daily activities of the animals. Welldefined game trails can potentially also serve for plot placement. In some environments, wild pigs may not preferentially use roads (or trails) as travel routes (e.g., Saunders et al. 1993). In those areas, placement of plots on roads would be inefficient and essentially the same as placing plots randomly throughout the area of interest.

The length of road segments used as plots to successfully monitor swine has varied considerably among studies. Road segments several meters in length have been effective in Australia (Allen et al. 1996), Florida (Engeman et al. 2002), and Texas (Engeman et al. 2001). For some large monitoring areas, road segments 0.8 to $1.6 \mathrm{~km}$ have been used as plots (Engeman et al. 2007; USDA 2011). Road surfaces for shorter plots are typically prepared by hand (smoothed with rake or broom), whereas the road surfaces for the longer plots are prepared mechanically by devices towed behind vehicles (chains, weighted chain-link fencing, and many other possibilities). This approach becomes most practical when track intrusions can be observed from the vehicle; thus, highly efficient observations can be made by slowly driving the road while towing the smoothing device. As observations are being made, the plots are being prepared for the next day's observations. Clearly, this long-plot approach is only viable where suitable road surfaces consistently exist throughout the area of interest. Longer road segments result in a greater distribution of track intrusion counts than for shorter plots, thereby resulting in superior statistical distributional properties for analyses.

In more arid environments, feral swine tracking stations are sometimes defined around water holes such as livestock ponds, where present (Lapidge et al. 2003; Mitchell 2003). Sample sizes (number of stations) may not be very high if the area does not contain many water holes. Nevertheless, if only a few water holes represent all the available water in the area, then they will likely reflect the pig population resident to that area. Because water hole locations are often designed for the benefit of livestock, their tracks often can obliterate those of wild pigs. 
There are a number of hindrances that can impede the use of tracking plot observations. Plainly, if the substrate is not amenable for plot preparation and observation (e.g., rocky substrates, vegetated tracks, etc.), then another monitoring method should be considered. Various events can also destroy individual or groups of plots, or change the detectability of prints on plots. Weather events (rain, wind), vehicle traffic, and livestock can all eliminate data from plots. Trained observers are also needed to distinguish between wild pig and similar ungulate tracks (e.g., sheep, goats, and deer), where present. Nevertheless, a general indexing paradigm (Engeman 2005) allows for unequal numbers of plot observations (missing data) among the days of observations.

\section{Camera traps}

Indirect observations with camera traps are becoming increasingly popular and often make detecting and counting animals possible whatever their activity period and without interruption. Size-wise, camera stations are probably most similar to the short-length tracking plots. Despite relatively high initial costs for cameras, this method opens the possibility of reduced labor cost for monitoring wildlife abundance (Bengsen et al. 2011; Silveira et al. 2003; Rowcliffe et al. 2008). The use of cameras has obvious advantages in efficiency over conventional survey techniques (like tracking plots): fewer field visits and reduced staff labor time and more data resulting from continued activation and reduced downtime from adverse weather conditions (Minta and Mangel 1989; De Bondi et al. 2010; Meek et al. 2012). For example, not including the cost of equipment, camera trapping was nine times cheaper than line transect counts for African forest ungulates (Rovero and Marshall 2009).

Besides the numbers of individuals (or individual visits) (e.g., Cowled et al. 2006), annual variations of population structure (unlike tracking plots) may be analyzed as well as the presence and variations in the numbers of sympatric species (like tracking plots). The age class of wild pigs may be determined from the photographs based on size and, in the case of wild boar, size in relation to visual marks and coloration (e.g., wild boar piglets with or without stripes). The first arrival of piglets in photographs within a year, the number of piglets per female, and the peak of birth may be compared spatially or temporally across years. Such indirect observations can also help detect the species where it is not known to exist (Akbada and Ayas 2012) and can also be used in some circumstances to assess reproductive success and survival rates, which in turn can be used to anticipate population density variations. Additionally, cameras potentially can be used to reduce animal wariness during observation sessions, providing a suite of supplementary data of interest to ecologists (Meek et al. 2012). Video recordings consume battery life and memory capacity, while still photographs reduce review time and are sufficient for detecting and counting individuals. Camera models designed to eliminate the tell-tale red glow common to conventional infrared cameras are less likely to alarm wild pigs.

Like other survey methods, careful consideration needs to be given to the study design and interpretation of data, but this can influence, and also be affected by, the type of camera chosen (Meek 2012). Mixing camera types can lead to inconsistency in data collection; cameras vary in sensor sensitivity, type of flash, field of view, detection zones, etc., all of which may affect detectability, reducing the ability to compare or use such data (Meek et al. 2012). Like all observation methods, various events can cause loss of data with cameras such as technological malfunctions, full or malfunctioning memory cards, and drained batteries, which can be exacerbated by extremes in temperature. Weather can also cause data loss, even if the camera is "weatherproof"; photos can be lost or uninterpretable by obscuring the lens with condensation, snow, or splashed water (or mud). Regular maintenance and calibration of the camera traps remains essential. Theft of camera traps can result in loss of equipment and data (Rovero and Marshall 2009) and may jeopardize the monitoring effort. In some highly public areas, camera traps are not suitable because of theft, and the incidental capture of people on images can create privacy issues and legal obligations for data management and use (Meek et al. 2012).

\section{Take rates}

Hunter take and catch per effort are widely applied methods for assessing relative abundance of wild pigs (Boitani et al. 1994; Fernandez-Llario et al. 2003; USDA 2011; Sarasa and Sarasa 2013). Application of the technique assumes a linear relationship between catch and population abundance, all removals are known, each individual has an equal probability of being captured, and that methods of removal are standardized (Caughley 1977; Thompson et al. 1998; Mitchell and Balogh 2007). Most of these assumptions are difficult to meet or unknown, potentially biasing results.

Hunter take per effort, often formulated as pigs per hunter-day, is frequently used to monitor populations. Relying on hunting bag data also means that data are only available from the times in which hunting seasons are scheduled, and comparative data are not available from sites where hunting is not allowed, such as parks or populated areas. Hunting indices are reliant upon factors affecting hunting intensity and effectiveness, including weather (Gaillard et al. 2003; Grauer and König 2009) and the cooperation and ability of hunters to complete accurate returns, which has proven difficult (Fernández-Llario et al. 2003). Hunt indices require large sampling areas to reduce bias (Siren et al. 2004). Moreover, hunters typically do not target all population 
segments equally, limiting the value of inferences to the total population and population structure (Braga et al. 2010; FestaBianchet 2007; Keuling et al. 2013; Plhal et al. 2011). To insure a valid index, effort expended, including by those hunters who do not bag an animal, also must be obtained (but often is not available).

Various measures are also applied when trapping animals such as rodents and predators using either live or kill traps (Krebs 1998). However, trap effort is more difficult to define when targeting pigs. In preparation to trap pigs, the trap and vicinity is usually baited until regular visitation by pigs becomes apparent. If no activity occurs, the trap is not set and is likely moved to start the procedure again. There still was "effort" even though the trap was not set and actively trapping, and this effort is difficult to account for. Additionally, not all animals are susceptible to trapping, leading to underestimates (e.g., up to $20 \%$, Choquenot et al. 1993).

\section{Dung counts}

Dung counts are used to survey many species of wildlife. The use of dung counts for indexing animal abundance requires systematic searches for dung. Two approaches can be used: determining the total amount of dung per area or monitoring the deposition of dung over time in fixed sampling plots (Putman 1984). Calculating the standing crop of dung is highly labor-intensive and generally impractical for monitoring programs (Mitchell and Balogh 2007). The rate of fecal accumulation is more commonly used as an index of wild pig abundance and can be strongly correlated with measured feral pig density (Hone 1995). While dung counts are relatively simple to undertake, with minimum equipment requirements, there are a number of influences that need to be considered to ensure that results remain valid. The quantity of dung produced per animal and the longevity of dung in the environment are dependent on a host of variables and therefore may vary somewhat independently of abundance (e.g., Hone 1988; Allen 2012), including the quantity and types of available forage and weather conditions. Given the existence of adequate data, defecation rate and decay rate in relation to season and habitat can be calculated and applied as adjustment factors for a specific geographical and temporal context (Massei et al. 1998). Assuming that $100 \%$ of the area of interest will not be searched for dung, sampling stations and time frames for dung deposition should be defined. Large plots are generally needed to ensure at least one dung sample can be detected per plot (Hone and Martin 1998; Hone 2012). Although swine population indexing using dung counts has been conducted without prior clearing of dung observation stations (Vicente et al. 2004), once stations are defined, it is best to clear each station of existing dung. After an a priori defined and fixed period of time, the station is again searched and dung counted. This minimizes the impacts of weather and other factors on dung availability and helps standardize index results spatially and temporally (Hone and Martin 1998). This approach works especially well for territorial canid species because they actively use and mark dirt roads and trails in usual daily movements, allowing road segments to be defined as stations (e.g., Stoddart et al. 2001). However, dung counts for feral pigs are more challenging because stations will likely have to be defined and searched in native terrain, making identification of station boundaries and detecting dung more difficult than on a road situation. Furthermore, wild pig feces tend to be aggregated, complicating sampling and estimation properties (Engeman et al. 1994; Hone 2012).

A station can be defined in a variety of manners such as a fixed-size plot or a fixed-length strip transect. Variable area transect sampling may be used as a potentially labor-saving alternative to strip transects, and research is available to provide guidance on the amount of searching that optimizes the tradeoff between labor and estimation quality (Engeman and Sugihara 1998; Parker 1979).

Similar to tracking plots, analysis of dung counts can be performed through either monitoring continuous measurements (i.e., changes in the amount of dung per plot) or binary measures (i.e., presence-absence of dung in plots). While using continuous measures has many demonstrated advantages (see "Measurements" section above), simply recording the presence-absence of dung on plots significantly reduces labor time (by $>50 \%$; Hone 1988) and may still provide an index of abundance (e.g., Hone 2002).

\section{DNA genotyping}

Going well beyond simply counting dung within stations, dung can be collected and genetically analyzed. Molecular techniques for individual genotyping have improved within the last two decades, providing an indirect way to count individual members of a population within an area (Broquet et al. 2007). Microsatellite DNA analyses allow assessment of the species, sex, and individual, and these may be used to assess the population genetic structure and population connectivity according to geographical barriers and gene flow (Cowled et al. 2008; Manel et al. 2003; Poteaux et al. 2009; Scandura et al. 2008). Results obtained by DNA analyses can be used as a "snapshot" to relate dung count indices to a minimum number of animals known to exist in the study area at the time of observation (genetic individualization). DNA genotyping can also be used with other methods (e.g., markrecapture, or catch per unit effort) to estimate population size (see following section). This may help quantify the impact of hunting (or other management measures) on population size and, thus, refine wild pig management.

Microsatellite markers currently used for wild pigs have been previously tested for Sus scrofa domestica (e.g., 
Alexander et al. 1996; Laval et al. 2000; Lowden et al. 2002; Rohrer et al. 1994). DNA may be extracted from hair and feces collected in the field. In contrast to tissue or blood sampling, such noninvasive samples can be collected without physical capture and visual contact, reducing some forms of potential sampling bias (Fickel and Hohmann 2006), leading to more precise estimates (Piggot and Taylor 2003; Poole et al. 2001; Mitchell and Balogh 2007). However, the noninvasive genetic sampling methods are often associated with technical problems due to low DNA quality and quantity, leading to genotyping errors (Broquet et al. 2007) and hence potentially biased estimates (Hoffman and Amos 2005). Several studies were conducted to optimize genotyping on such noninvasive samples and assure it maximum reliability. As an example, Kolodziej et al. (2012) recommended for feces a specific four-loci combination for a reliable individual identification and population size estimation in the wild boar population they tested. Fresh samples are best for analysis and DNA sampling requires the means and materials to preserve the samples in the field.

Although costs for DNA analyses have been decreasing as the technology has become more ubiquitous, analyses of multiple samples can be a time-consuming and expensive proposition, especially considering that not all samples taken from the environment will have sufficient quantity or quality of DNA to identify an individual. Collection of samples also needs to consider assumption violations through capture heterogeneity (e.g., Ebert et al. 2010), including assumptions of equal capture rates between sex, age, and social classes, important but often overlooked assumptions when analyzing DNA studies.

Animal marking and capture-mark-recapture methods

Wild pig population densities are sometimes estimated using capture-mark-recapture (CMR) methods, where animals are usually captured and marked, often with ear tags (e.g., Hebeisen et al. 2008). However, CMR in wild pigs is time-, cost-, and labor-intensive and highly prone to capture heterogeneity among age and sex classes (Baber and Coblentz 1986; Sweitzer et al. 2000), and marks (e.g., ear tags) may be lost, resulting in violation of analytical assumptions and estimates of questionable quality. Moreover, when pigs are trapped for the purpose of marking and then release, there can be an understandable reluctance to release a potentially destructive, often invasive species back into the environment. The same heterogeneity issues as indicated earlier also hold forth when attempting "captures" using baited hair traps for genotyping (Ebert et al. 2010). Capture heterogeneity weakens population estimates, and if the population is also not closed, density estimates by CMR become more uncertain. Estimating wild pig population size using fecal
DNA and CMR modeling shows promise given sufficient detection probability of feces (Ebert et al. 2012).

An alternative marking approach which can alleviate the costs and effort involved in physical capture is to use baits containing marker agents. This approach may also alleviate possible biasing effects, where the probability of initial capture of animals differs from the probabilities of recapture. A wide variety of substances including dyes, radioactive and stable isotopes, inert particles, and systemically absorbed chemicals have been used as bait markers on many species (Savarie et al. 1992; Fry and Dunbar 2007). Depending on the marker substance, the mark may be detectable on internal tissues collected from hunted animals or in hair and whiskers (Ballesteros et al. 2012; Fisher 1999). As an example, systemic markers such as ethyl-iophenoxic acid and analogs may be detected in the blood, muscle, and liver of hunted wild pigs (e.g., Ballesteros et al. 2011; Massei et al. 2009; Sage et al. 2013) and may be used to provide information on temporal or spatial patterns of bait consumption. One potential source of bias is that there may be subjectivity in determining whether an individual actually is marked because indirect marking does not always produce clear-cut marks. In these cases, the consumption of different analogs distributed at different times may be considered as recaptures. However, different analogs have different rates of disappearance so caution should be used when designing trials that employ more than one analog (Massei et al. 2009).

\section{Spotlight counts}

Wild pigs are typically most active at night and spotlight counts from slowly moving vehicles at night have been used to create abundance indices and line transect population density estimates for wild pigs (e.g., Hone and Pedersen 1980; Choquenot et al. 1993). Creating an abundance index from spotlight counts requires careful design and planning to avoid bias and confounding. Indices can be based on counts along defined road segments (i.e., stations), or as the number observed per unit distance. However, obtaining valid observations can be problematic. First, the tapetum lucidum of wild pigs are not reflective like other animals, making spotlight sightings more difficult (Acevedo et al. 2007; Focardi et al. 2001). The ability to observe wild pigs using a spotlight can vary greatly from observer to observer and also among different types of vegetation (e.g., Twigg et al. 1998).

Using spotlight counts to additionally measure distance to the animals could potentially allow calculation of line transect density estimates (e.g., Buckland et al. 1993; Burnham et al. 1980; Krebs 1998), but this adds another layer of observational difficulty when it is imperative to not violate necessary assumptions for valid estimation (e.g., Burnham et al. 1980; Buckland et al. 1993). Moreover, to achieve accurate density estimates for an area requires many 
sightings, with Buckland et al. (1993) recommending at least 60 . Thus, this method may only be useful for very large areas or dense populations, or require intensive resampling over many days, and therefore may not validly chronicle population reductions in a given area. Also, when obtaining sightings, one of the estimation assumptions is that animals are only observed once per transect, and animals from one transect are not "flushed" to another. Other easily violated assumptions include the following: animals do not move in response to the observer prior to being observed, all animals on the transect are observed with probability one, the perpendicular distances to each sighting are estimated accurately, and sighting probability decreases monotonically with distance from the observer (e.g., Burnham et al. 1980; Buckland et al. 1993). The use of spotlight counts to monitor pig populations would most likely be useful only in open country with a high degree of sampling effort (Choquenot et al. 1990).

\section{Night vision and thermal imaging}

One problem with direct observation methods such as spotlight or aerial surveys is the relative inefficiency in detecting sufficient numbers to provide reliable density estimates or index values. The use of new or improved technologies that increase the probability of detection can help improve population monitoring methods, data collection, and estimation. Whether used for ground or aerial survey, light-amplifying vision systems or thermal imaging can be used to detect and observe animals at night (Allison and Destefano 2006).

Light amplification systems, commonly known as night vision systems (NV), require a minimum level of ambient light, so "blackout" conditions can limit its usefulness. In contrast, thermal imaging (TI) needs no light to be effective and has been the focus of many recent applications for wildlife monitoring practices. Thermal imaging devices detect infrared radiation (heat) emitted from an object (Speakman and Ward 1998); the contrasting heat emitted from animals and the environment allows animals to be detected. Such characteristics allow TI to detect animals under most weather conditions, often through foliage and at great distances (e.g., $>500 \mathrm{~m}$ for wild pig), even on occasion during daylight (e.g., Haridas et al. 2011). Thermal imaging technology can substantially reduce disturbance and flushing of animals traditionally expected from spotlight surveys (Focardi et al. 2001; Franzetti et al. 2012), improving wild pig detectability. Thermal imaging methods have been found more effective than spotlighting for wild pigs (Focardi et al. 2001). Despite the advantages of improved detectability using either TI or NV, creating a reliable abundance index or density estimate depends on the same careful design, implementation, and assumptions as line transect or distance sampling techniques (see spotlight section above), which can be difficult. Obtaining a sufficient number of observations may still be problematic; for low density populations $\left(<10\right.$ animals $\left.\mathrm{km}^{2}\right)$, it remains difficult or costly to obtain reliably precise estimates, despite the use of infrared technology (Gill and Brandt 2010). Additionally, the price of suitable equipment (particularly of the TI type) may be prohibitive for many, although the costs of such equipment are falling and can be offset through repeated use over many sampling periods (Franzetti et al. 2012). McCafferty (2007) summarized the advantages, limitations, and constraints in the study design for thermal imaging for mammals.

New methods are proposed to reduce animal disturbance and to be effective in areas where access is particularly difficult. For example, thermal imaging video recordings from towers and from a helium-inflated airship have been used to locate and estimate the numbers of recently introduced Eurasian wild boar in Singapore (Haridas et al. 2011).

\section{Aerial surveys}

In an open country especially, aerial surveys can potentially be used to assess pig populations over large areas. Observations can be made using observers or using video or TI recording devices that can be examined later. Usually there would be at least one observer on each side of the aircraft. Careful training and testing is required to assure similar observation abilities among observers (e.g., Beard 1999). Even so, careful experimental design should be applied to minimize and account for biasing influences due to potential differences in observational abilities between observers.

Data from aerial surveys can be accumulated as a fixed width strip transect context where all animals within a fixed distance of the aircraft are assumed to be counted (once only), or as a line transect context where distances are measured from the aerial transect line to animals. More recently, the development of a combination of mark-recapture and line transect methods (known as mark-recapture distance sampling) can help overcome some of the potential biases associated with each separate technique (Fewster and Pople 2008). Strip transect and line transect data can be used to calculate population density estimates, subject to meeting the associated analytical assumptions, which may be difficult to do (Buckland et al. 1993; Krebs 1998). Both observation methods can also be used to formulate abundance indices as well (Engeman 2005).

The methods used to assess population abundance can have profound effects on species behavior or activity, resulting in biased results. This is well-documented for line transect observations (e.g., Burnham et al. 1980) and is further validated by other examples such as feral pigs acting dead during aerial surveys following aerial gunning as control (Saunders and Bryant 1988). Caughley (1977) further discusses individual 
and species behavior relative to trapping devices and survey methods affecting the quality of data.

\section{Using plot occupancy for abundance estimation}

This approach is sometimes applied to develop abundance estimates for large areas using presence-absence observations derived from map units into which the area has been geographically divided. The pattern of occurrence of a species among the units is assumed related to abundance, spatial distribution patterns of the species, the size of the units, and the probability of detecting the species within a unit (He and Gaston 2000; MacKenzie et al. 2002; Royle and Nichols 2003). Building on MacKenzie et al. (2002), Royle and Nichols (2003) developed a model allowing abundance to be estimated using a mixture of unit-specific unconditional detection probabilities that depend only on the number of animals available for detection. Stanley and Royle (2005) advanced this work to incorporate the use of indirect abundance indices from the units for use in abundance estimation. To produce an abundance estimate from occupancy data requires a variety of often hard-to-meet assumptions, including population closure, and each map unit with swine is accurately assessed as having them and that distinct individuals cannot be detected in $>1$ unit during the observation session. Even if assumptions are met, occupancy methods do not appear well-suited for gregarious (Bengsen et al. 2011) and/or ubiquitous species in areas where they are wellestablished, because even large changes in abundance potentially could go undetected between monitoring sessions. Most likely, this method would primarily find utility in assessing swine populations at the leading edges of range expansion (or perhaps contraction).

\section{Discussion}

Worldwide, wild pig populations are expanding in numbers and distribution (Corn et al. 2005; Massei et al. 2011). Estimating local abundance or monitoring population trends is crucial to assess the impact of methods aimed at reducing population size or impact. This review highlighted that, when considering how to monitor wild pig populations, one method does not fit all situations. For instance, there are many environmental circumstances in which monitoring would take place, a wide range of resources such as personnel and equipment that might be available to carry out monitoring, many methodological choices for observing and quantitatively monitoring wild swine, and a variety of analytical approaches for producing metrics of pig abundance. Ideally, methods need to be sensitive to reflect changes in abundance, rely on a minimum number of assumptions, be associated with a valid statistical method to allow spatial or temporal comparisons, and above all be practical for use under field conditions. Failure to meet one or more of these considerations will either affect the ability to implement the monitoring technique or the usefulness of the results to monitor populations. With these criteria in mind, our review provided some principles and considerations on monitoring methods for users to make informed decisions regarding method(s) best suited to their combination of objectives, circumstances, and resources.

In parallel with an increase in wild pig numbers and distribution, human-wild pig conflicts are growing, especially where pigs are an invasive species. At the same time, the task of managing wild pigs is often placed with local public or private entities that require user-friendly, inexpensive methods to assess pig abundance. The environmental and economic impact of wild pigs is often a function of local densities (Hone 2002) and can be useful for identifying a threshold above which the local number of wild pigs is incompatible with human interests and the density of animal must be reduced. Monitoring abundance also is crucial to studying the epidemiology of wildlife diseases, especially when making management decisions on timing and placement of actions to eradicate diseases. It would be unrealistic to expect local entities to have broad expertise or resources available for efficiently developing protocols for monitoring wild pig populations. Thus, simple, repeatable, user-friendly methods to track population trends or evaluate the impact of population management methods are particularly valuable.

The key to successful monitoring is to rigorously use valid statistical design concepts. Habitat, physical and human resources, size and characteristics of the area monitored, intervals between monitoring occasions, and time span across which monitoring is to take place all will influence and guide which monitoring methods are optimal for application. Monitoring methods should be selected carefully, as the same method(s) should consistently be used through time in the same way to insure valid comparisons or assessments of trends through time. Where monitoring of several independent areas is proposed, thought should also be given to standardizing methods to allow meaningful comparisons to be made. Simultaneous application of multiple monitoring methods may provide added confidence in results and insurance against loss of the ability to apply a particular method.

In recent years, technological and methodological developments have resulted in much refinement and application of advanced techniques like the use of remote cameras and DNA analyses. The cost of such techniques (especially cameras) has, and will continue to decline, improving the costeffectiveness and uptake of such techniques by practitioners. While these technologies can be purchased and deployed in the field relatively easily and quickly, users must carefully consider the application of such technologies to each individual study, paying particular attention to the aims of the 
monitoring and the appropriate means of analyses. This has particularly been the case for camera traps, due to the "appealing" nature of capturing images of wild animals, but such devices can effectively become "an expensive toy" if not used appropriately (Meek et al. 2012). It typically is preferable to use established, proven techniques unless sufficient time and resources can be provided to develop and calibrate new methods or technologies. While new developments are exciting and have the potential to revolutionize monitoring programs, new methods must be tested against simultaneously applied traditional methods. Such techniques must consider sound design principles to ensure that monitoring fulfills its objectives and provides robust, repeatable estimates of population abundance and trends.

\section{References}

Acevedo P, Vicente J, Höfle U, Cassinello J, Ruiz-Fons F, Gortazar C (2007) Estimation of European wild boar relative abundance and aggregation: a novel method in epidemiological risk assessment. Epidemiol Infect 135:519-527

Akbada B, Ayas Z (2012) Camera trap study on inventory and daily activity patterns of large mammals in a mixed forest in northwestern Turkey. Mamm 76:43-48

Alexander LJ, Rohrer GA, Beattie CW (1996) Cloning and characterization of 414 polymorphic porcine microsatellites. Anim Genet 27:137-148

Allison NL, Destefano S (2006) Equipment and techniques for nocturnal wildlife studies. Wildl Soc Bull 34:1036-1044

Allen BL (2012) Scat happens: spatiotemoral fluctuation in dingo scat collection rates. Austral J Zool 60:137-140

Allen BL, Engeman RM, Allen LR (2011) Wild dogma: an examination of recent "evidence" for dingo regulation of invasive mesopredator release in Australia. Curr Zool 57:568-583

Allen LR, Engeman R (1995) Assessing the impact of dingo predation on wildlife using an activity index. In: Proceedings of the 10th Australian Vertebrate Pest Conference. Hobart, Tasmania, pp 72 79

Allen L, Engeman RM, Krupa H (1996) Evaluation of three relative abundance indices for assessing dingo populations. Wildl Res 23:197-206

Anderson DR (2001) The need to get the basics right in wildlife field studies. Wildl Soc Bull 29:1294-1297

Baber DW, Coblentz BE (1986) Density, home range, habitat use, and reproduction in feral pigs on Santa Catalina Island. J Mamm $67: 512-525$

Ballesteros C, Sage M, Fisher P, Massei G, Mateo R, de la Fuente J, Rossi S (2012) Iophenoxic acid as a bait marker for wild mammals: efficacy and safety considerations. Mamm Rev 43:156-166

Ballesteros C, Vicente J, Carrasco-Garcia R, Mateo R, de la Fuente J, Gortazar C (2011) Specificity and success of oral-bait delivery to Eurasian wild boar in Mediterranean woodland habitats. Euro J Wildl Res 57:749-757

Beard LA (1999) Training observers. Aust Zool 31:287-291

Bengsen AJ, Leung LK-P, Lapidge SJ, Gordon IJ (2011) Using a general index approach to analyze camera-trap abundance indices. J Wildl Manag 75:1222-1227
Blaum N, Engeman RM, Wasiolka B, Rossmanith E (2008) Indexing small mammalian carnivores in the southern Kalahari, South Africa. Wildl Res 35:72-79

Boitani L, Mattei L, Nonis D, Corsi F (1994) Spatial and activity patterns of wild boars in Tuscany. J Mamm 75:600-612

Braga C, Alexandre N, Fernandez-Llario P, Santos P (2010) Wild boar (Sus scrofa) harvesting using the espera hunting method: side effects and management implications. Eur J Wildl Res 56:465-469

Broquet T, Menard N, Petit E (2007) Non-invasive population genetics: a review of sample source, diet, fragment length and microsatellite motif effects on amplification success and genotyping error rates. Conserv Genet 8:249-260

Buckland ST, Anderson DR, Burnham KP, Laake JL (1993) Distance sampling: estimating abundance of biological populations. Chapman and Hall, London

Burnham KP, Anderson DR, Laake JL (1980) Estimation of density from line transect sampling of biological populations. Wildl Monogr 72:1-202

Campbell TA, Long DB, Massei G (2011) Efficacy of the BoarOperated-System to deliver baits to feral swine. Prev Vet Med 98:243-249

Caughley G (1977) Analysis of vertebrate populations. Wiley, New York

Caughley G, Sinclair A (1994) Wildlife ecology and management. Blackwell Science, Cambridge

Choquenot D, Kay B, Lukins BS (1990) An evaluation of warfarin for the control of feral pigs. J Wildl Manag 54:353-359

Choquenot D, Kilgour RJ, Lukins BS (1993) An evaluation of feral pig trapping. Wildl Res 20:15-22

Choquenot D, Lukins B, Curran G (1997) Assessing lamb predation by feral pigs in Australia's semi-arid rangelands. J App Ecol 34:14451454

Choquenot D, Mcllroy J, Korn T (1996) Managing vertebrate pests: feral pigs. Bureau of Resource Sciences, Australian Government Publishing Service, Canberra

Corn JL, Cumbee JC, Chandler BA, Stallknecht DE, Fischer JR (2005) Implication of feral swine expansion: expansion of feral swine in the United States and potential implication for domestic swine. Feral Swine Subcommittee on Brucellosis and Pseudorabies. United States Animal Health Association, St. Joseph, pp 295-297

Corn JL, Cumbee JC, Barfoot R, Erickson GA (2009) Pathogen exposure in feral swine populations geographically associated with high densities of transitional swine premises and commercial swine production. J Wildl Dis 43:713-721

Cowled BD, Gifford E, Smith M, Staples L, Lapidge SJ (2006) Efficacy of manufactured PIGOUT ${ }^{\circledR}$ baits for localised control of feral pigs in the semi-arid Queensland rangelands. Wildl Res 33:427-437

Cowled BD, Aldenhoven J, Odeh IO, Garrett T, Moran C, Lapidge SJ (2008) Feral pig population structuring in the rangelands of eastern Australia: applications for designing adaptive management units. Conserv Genet 9:211-224

De Bondi N, White JG, Stevens M, Cooke R (2010) A comparison of the effectiveness of camera trapping and live trapping for sampling terrestrial small-mammal communities. Wildl Res 37:456-465

Ebert C, Huckschlag D, Schulz HK, Hohmann U (2010) Can hair traps sample wild boar (Sus scrofa) randomly for the purpose of noninvasive population estimation? Eur J Wildl Res 56:583-590

Ebert C, Knauer F, Spielberger B, Thiele B, Hohmann U (2012) Estimating wild boar Sus scrofa population size using faecal DNA and capture-recapture modelling. Wildl Biol 18:142-152

Elledge AE (2011) Habitat preferences and environmental impacts of feral pigs (Sus scrofa) in lowland tropical rainforests of northeastern Australia. Dissertation. University of Queensland, Brisbane

Engeman RM (2003) More on the need to get the basics right: population indices. Wildl Soc Bull 31:286-287 
Engeman R (2005) Indexing principles and a widely applicable paradigm for indexing animal populations. Wildl Res 32:202-210

Engeman R, Allen L (2000) Overview of a passive tracking index for monitoring wild canids and associated species. Integr Pest Manag Rev 5:197-203

Engeman RM, Betsill C, Ray T (2011) Making contact: rooting out the potential for exposure of commercial production swine facilities to feral swine. EcoHealth 8:76-81

Engeman RM, Constantin B, Nelson M, Woolard J, Bourassa J (2001) Monitoring changes in feral swine population and spatial distribution. Environ Conserv 28:235-240

Engeman RM, Duffiney A, Braem S, Olsen C, Constantin B, Small P, Dunlap J, Griffin JC (2010) Dramatic and immediate improvements in insular nesting success for threatened sea turtles and shorebirds following predator management. J Exper Mar Biol Ecol 395:147-152

Engeman RM, Otis DL, Bromaghin JF, Dusenberry WE (1989) On the use of the $\mathrm{R}_{50}$. In: Fagerstone F, Curnow R (eds) Vertebrate pest control and management materials. Vol 6, STP1055. American Society for Testing and Materials, Philadelphia, pp 13-18

Engeman RM, Pipas MJ, Gruver KS, Allen L (2000) Monitoring coyote populations with a passive activity index. Wildl Res 27:553-557

Engeman RM, Pipas MJ, Gruver KS, Bourassa J, Allen L (2002) Plot placement when using a passive tracking index to simultaneously monitor multiple species of animals. Wildl Res 29:85-90

Engeman RM, Stevens A, Allen J, Dunlap J, Daniel M, Teague D, Constantin BU (2007) Feral swine management for conservation of an imperiled wetland habitat: Florida's vanishing seepage slopes. Biol Conserv 134:440-446

Engeman RM, Sugihara RT (1998) Optimization of variable area transect sampling using Monte Carlo simulation. Ecol 79:1425-1434

Engeman RM, Sugihara RT, Pank LF, Dusenberry WE (1994) A comparison of plotless density estimators using Monte Carlo simulation. Ecol 75:1769-1779

Engeman RM, Whisson DA (2003) A visual method for indexing muskrat populations. Intern Biodeterior Biodegrad 52:101-106

Engeman RM, Witmer GW (2000) IPM strategies: indexing difficult to monitor populations of pest species. In: Salmon TP, Crabb AC (eds) Proceedings 19th vertebrate pest conference. University of California, Davis, pp 183-189

Fernandez-Llario P, Matoes-Quesada PM, Silverio A, Santos P (2003) Habitat effects and shooting techniques on two wild boar (Sus scrofa) populations in Spain and Portugal. Z Jagdwiss 49:120-129

Festa-Bianchet M (2007) Ecology, evolution, economics and ungulate management. In: Fullbright T, Hewitt D (eds) Wildlife science: linking ecological theory and management applications. CRC, Boca Raton, pp 183-202

Fewster RM, Pople AR (2008) A comparison of mark-recapture distance-sampling methods applied to aerial surveys of eastern grey kangaroos. Wildl Res 35:320-330

Fickel J, Hohmann U (2006) A methodological approach for noninvasive sampling for population size estimates in wild boars (Sus scrofa). Eur J Wildl Res 52:28-33

Fisher P (1999) Review of using rhodamine B as a marker for wildlife studies. Wildl Soc Bull 27:318-329

Focardi S, De Marinis AM, Rizzotto M, Pucci A (2001) Comparative evaluation of thermal infrared imaging and spotlighting to survey wildlife. Wildl Soc Bull 29:133-139

Franzetti B, Ronchi B, Marini F, Scacco M, Calmanti R, Calabrese A, Paola A, Paolo M, Focardi S (2012) Nocturnal line transect sampling of wild boar (Sus scrofa) in a Mediterranean forest: longterm comparison with capture-mark-resight population estimates. Eur J Wildl Res 58:385-402

Fry T, Dunbar M (2007) A review of biomarkers used for wildlife damage and disease management. In: Nolte DL, Arjo WM, Stalman DH (eds) Proceedings of the 12th wildlife damage management conference, pp 216-222
Gaillard JM, Duncan P, Delorme D, van Laere G, Pettorelli N, Maillard D, Renaud G (2003) Effects of hurricane Lothar on the population dynamics of roe deer. J Wildl Manage 67:767-773

Gill R, and Brandt G (2010) Estimating density of British Wild Boar populations using thermal imaging. 8th International Symposium on Wild Boar and other Suids, York, UK, p 45

Grauer A, König A (2009) Management of chamois in Bavaria (Germany): the importance of game activities in scabies control. Wildl Biol Pract 5:115-127

Haridas S, Diong CH, Seet G, Lee NSL (2011) Conundrum of the Eurasian wild pig Sus scrofa status on the island of Singapore: human wildlife and environmental conflict. In: Jacob J, Esther A (eds) 8th European vertebrate pest management conference. Julius Kühn-Archiv, Quedlinburg, p 432

He F, Gaston KJ (2000) Estimating species abundance from occurrence. Am Nat 156:553-559

Hebeisen C, Fattebert J, Baubet E, Fischer C (2008) Estimating wild boar (Sus scrofa) abundance and density using capture-resights in Canton of Geneva, Switzerland. Eur J Wildl Res 54:391-401

Hoffman J, Amos W (2005) Microsatellite genotyping errors: detection approaches, common sources and consequences for paternal exclusion. Mol Ecol 14:599-612

Hone J (1988) Evaluation of methods for ground survey of feral pigs and their sign. Acta Theriol 33:451-465

Hone J (1995) Spatial and temporal aspects of vertebrate pest damage with emphasis on feral hogs. J Appl Ecol 32:311-319

Hone J (2002) Feral pigs in Namadgi National Park, Australia: dynamics, impacts and management. Biol Conserv 105(2):231-242

Hone $\mathrm{H}$ (2012) Applied population and community ecology: the case of feral pigs in Australia. Wiley-Blackwell, Oxford

Hone J, Martin W (1998) A study of dung decay and plot size for surveying feral pigs using dung counts. Wildl Res 25:255-260

Hone J, Pederson H (1980) Changes in a feral pig population after poisoning. In: Clark JP, Marsh RE (eds) Proceedings of the 9th vertebrate pest conference. University of California, Davis, pp 176-182

Jiang GS, Ma JZ, Zhang MH (2006) Spatial distribution of ungulate responses to habitat factors in Wandashan forest region, northeastern China. J Wildl Manag 70:1470-1476

Johnson DH (2008) In defense of indices: the case of bird surveys. J Wildl Manag 72:857-868

Koichi K, Sangha KK, Cottrell A, Gordon IJ (2012) Aboriginal Rangers' perspectives on feral pigs: are they a pest or resource? A case study in the Wet Tropics World Heritage Area of northern Queensland. J Aust Indig Issues 15:2-19

Keuling O, Baubet E, Duscher A, Ebert C, Fischer C, Monaco A, Podgórski T, Prevot C, Ronnenberg K, Sodeikat G, Stier N, Thurfjell H (2013) Mortality rates of wild boar Sus scrofa L. in central Europe. Eur J Wildl Res. doi:10.1007/s10344-013-0733-8

Kolodziej K, Theissinger K, Brün J, Schulz H, Schulz R (2012) Determination of the minimum number of microsatellite markers for individual genotyping in wild boar (Sus scrofa) using a test with close relatives. Euro J Wildl Res 58:621-628

Krebs CJ (1998) Ecological methodology. Benjamin/Cummings, Menlo Park

Lapidge S, Derrick M, Conroy J (2003) Adaptive management and demography of feral pigs in southern Queensland. In: Lapidge SJ (ed) Proceedings of the Feral Pig Action Agenda. James Cook University Cairns. Pest Animal Control Cooperative Research Centre, Canberra, pp 28-30

Lapidge S, Wishart J (2010) The development of the ultimate feral pig bait hopper - are we heading in the right direction? 2010 International wild pig conference, Pensacola, pp 11-13

Laval G, Iannuccelli N, Legault C, Milan D, Groenen MA, Giuffra E, Andersson L, Nissen PH, Jorgensen CB, Beeckmann P, Geldermann H, Foulley JL, Chevalet C, Ollivier L (2000) Genetic diversity of eleven European pig breeds. Genet Sel Evol 32:187-203 
Leaper R, Massei G, Gorman ML, Aspinall R (1999) The feasibility of reintroducing wild boar (Sus scrofa) to Scotland. Mamm Rev 29:239-259

Leidloff AC (2000) Habitat Utilisation by the Grassland Melomys (Melomys burtoni) and the swamp rat (Rattus lutrelus) in a Coastal Heathland of Bribie Island, South-East Queensland. Dissertation, Queensland University of Technology, Brisbane, Queensland, Australia

Lowden S, Finlayson H, Macdonald A, Downing A, Goodman S, Leus K, Kaspe L, Wahyuni E, Archibald A (2002) Application of Sus scrofa microsatellite markers to wild suiformes. Conserv Genet 3:347-350

Lowe S, Browne M, Boudjelas S, De Poorter M (2004) 100 of the world's worst invasive alien species: a selection from the Global Invasive Species Database. Invasive Species Specialist Group, Auckland

Manel S, Schwartz MK, Luikart G, Taberlet P (2003) Landscape genetics: combining landscape ecology and population genetics. Trends in Ecol Evol 18:189-197

Massei G, Bacon P, Genov P (1998) Fallow deer and wild boar pellet group disappearance in a Mediterranean area. J Wildl Manage 62:1086-1094

Massei G, Coats J, Quy R, Storer K, Cowan DP (2010) The BOS (BoarOperated-System): a novel method to deliver baits to wild boar. J Wildl Manage 74:333-336

Massei G, Genov P (2004) The environmental impact of wild boar. Galemys 16:135-145

Massei G, Jones A, Platt T, Cowan DP (2009) Iophenoxic acid as longterm marker for wild boar. JWildl Manage 73:458-461

Massei G, Roy S, Bunting R (2011) Too many hogs? A review of methods to mitigate impact by wild boar and feral hogs. Hum Wildl Interact 5:79-99

MacKenzie DI, Nichols JD, Lachman GB, Droege S, Royle JA, Langtimm CA (2002) Estimating site occupancy rates when detection probabilities are less than one. Ecol 83:2248-2255

McCafferty DJ (2007) The value of infrared thermography for research on mammals: previous applications and future directions. Mamm Rev 37:207-223

McKelvey KS, Pearson DE (2001) Population estimation with sparse data: the role of estimators versus indices revisited. Can J Zool 79:1754-1765

Meek PD (2012) Refining and improving the use of camera trap technology for wildlife management and research in Australia and New Zealand. The Winston Churchill Memorial Trust of Australia, Canberra

Meek PD, Ballard G, Fleming P (2012) An Introduction to camera trapping for wildlife surveys in Australia. PestSmart Toolkit publication. Invasive Animals Cooperative Research Centre, Canberra

Meriggi A, Grangi A, Mateucci C, Sacci O (1996) The feeding habits of wolves in relation to large prey availability in Northern Italy. Ecogr 19:287-295

Meurk CS (2011) Loving nature, killing nature, and the crises of caring: an anthropological investigation of conflicts affecting feral pig management in Queensland. The University of Queensland, Brisbane

Meyerson L, Engeman RM, O'Malley R (2008) Tracking non-native vertebrate species: indicator design for the United States. Wildl Res 35:235-241

Minta S, Mangel M (1989) A simple population estimate based on simulation for capture-recapture and capture-resight data. Ecol 70:1738-1751

Mitchell B, Balogh S (2007) Monitoring techniques for vertebrate pests - feral pigs. NSW Department of Agriculture, Orange

Mitchell J (2003) Feral pig research in north Queensland. In: Lapidge SJ (ed) Proceedings of the feral pig action agenda. James Cook University, Cairns. Pest Animal Control Cooperative Research Centre, Canberra, pp 23-25
Otis DL, Burnham KP, White GC, Anderson DR (1978) Statistical inference from capture data on closed animal populations. Wildl Monogr 62:3-135

Parker KR (1979) Density estimation by variable area transect. J Wildl Manage 43:484-492

Piggott MP, Taylor AC (2003) Extensive evaluation of faecal preservation and DNA extraction methods in Australian native and introduced species. Aust J Zool 51:341-355

Plhal R, Kamler J, Homolka M, Adamec Z (2011) An assessment of the applicability of photo trapping to estimate wild boar population density in a forest environment. Folia Zool 60(3):237-246

Poole KG, Mowat G, Fear DA (2001) DNA-based population estimate for grizzly bears Ursus arctos in northeastern British Columbia, Canada. Wildl Biol 7:105-115

Poteaux C, Baubet E, Kaminski G, Brandt S, Dobson F, Baudoin C (2009) Socio-genetic structure and mating system of a wild boar population. J Zool 278:116-125

Putman RJ (1984) Facts from faeces. Mamm Rev 14:79-97

Ramsay BJ (1994) Commercial use of wild animals in Australia. Bureau of Resource Sciences, Australian Government Publishing Service, Canberra

Rohrer GA, Alexander LJ, Keele JW, Smith TP, Beattie CW (1994) A microsatellite linkage map of the porcine genome. Genet 136:231-245

Rovero F, Marshall AR (2009) Camera trapping photographic rate as an index of density in forest ungulates. J Appl Ecol 46:1011-1017

Rowcliffe JM, Field J, Turvey ST, Carbone C (2008) Estimating animal density using camera traps without the need for individual recognition. J Appl Ecol 45:1228-1236

Royle JA, Nichols JD (2003) Estimating abundance from repeated presence-absence data or point counts. Ecol 84:777-790

Ruiz-Fons F, Segales J, Gortazar C (2008) A review of viral diseases of the European wild boar: effects of population dynamics and reservoir role. Vet J 176:158-169

Ryan DA, Heywood A (2003) Improving the precision of longitudinal ecological surveys using precisely defined observational units. Environmetrics 14:83-293

Sage M, Fourel I, Lahoreau J, Siat V, Berny P, Rossi S (2013) Iophenoxic acid derivatives as markers of oral baits to wildlife: new tools for their detection in tissues of a game species and safety considerations for human exposure. Environ Sci Pollut Res 20:2893-2904

Sarasa M, Sarasa J-A (2013) Intensive monitoring suggests population oscillations and migration in wild boar Sus scrofa in the Pyrenees. Ani Biodivers Cons 36:79-88

Saunders G, Bryant H (1988) The evaluation of a feral pig eradication program during a simulated exotic disease outbreak. Aust Wildl Res 15:73-81

Saunders G, Kay B, Nicol H (1993) Factors affecting bait uptake and trapping success for feral pigs (Sus scrofa) in Kosciusko National Park. Wildl Res 20:653-665

Savarie PJ, Johns BE, Gaddis SE (1992) A review of chemical and particle marking agents used for studying vertebrate pests. Proceedings of the Fifteenth Vertebrate Pest Conference. University of Nebraska, Lincoln, pp 252-257

Scandura M, Iacolina L, Crestanello B, Pecchioli E, Di Benedetto F, Russo V et al (2008) Ancient vs. recent processes as factors shaping the genetic variation of the European wild boar: are the effects of the last glaciation still detectable? Mol Ecol 17:1745-1762

Seward N, VerCauteren K, Witmer G, Engeman R (2004) Feral swine impacts on agriculture and the environment. Sheep and Goat Res J 19:34-40

Silveira L, Jacomo ATA, Diniz JAF (2003) Camera trap, line transect census and track surveys: a comparative evaluation. Biol Conserv 114:351-355

Siren A, Hambäck P, Machoa J (2004) Including spatial heterogeneity and animal dispersal when evaluating hunting: a model analysis and empirical assessment in an Amazonian community. Conserv Biol 18:1315-1329 
Speakman JR, Ward S (1998) Infrared thermography: principles and applications. Zool 101:224-232

Stanley TR, Royle JA (2005) Estimating site occupancy and abundance using indirect detection indices. J Wildl Manage 69:874-883

Stoddart, Griffiths RE, Knowlton FF (2001) Coyote responses to changing jackrabbit abundance affect sheep predation. J Range Manag 54:15-20

Sweitzer RA, Van Vuren D, Gardner IA, Boyce WM, Waithman JD (2000) Estimating sizes of wild pig populations in the north and central coast regions of California. J Wildl Manag 64:531543

Theuerkauf J, Rouys S (2008) Habitat selection by ungulates in relation to predation risk by wolves and humans in the Bialowieza Forest, Poland. Forest Ecol Manag 256:1325-1332

Thomas J, Engeman RM, Tillman E, Fischer J, Glueck D, Felix R, Orzell S, Avery M (2013) Optimizing line intercept sampling and estimation for feral swine damage levels in sensitive wetland plant communities. Environ Sci Pollut Res 20:1503-1510

Thompson WL, White GC, Gowan C (1998) Monitoring vertebrate populations. Academic, San Diego

Twigg LE, Lowe TJ, Gray GS, Martin GR, Wheeler AG, Barker W (1998) Spotlight counts, site fidelity and migration of European rabbits (Oryctolagus cuniculus). Wildl Res 25:113-122

Vicente J, Segalés J, Höfle U, Balasch M, Plana-Durán J, Domingo M, Gortázar C (2004) Epidemiological study on porcine circovirus type 2 (PCV2) infection in the European wild boar (Sus scrofa). Vet Res 35:243-253

USDA/Wildlife Services/National Wildlife Research Center (2011) Development, implementation and evaluation of management tools to reduce feral swine damage at Avon Park AFR, Florida. Annual Report to U.S. DoD/Avon Park Air Force Range. National Wildlife Research Center, Fort Collins 